\title{
Mechanical Properties of Magnetically Oriented Epoxy
}

\author{
M. S. AL-HAIK, ${ }^{1,2}$ H. GARMESTANI, ${ }^{3}$ D. S. LI, $^{3}$ M. Y. HUSSAINI, ${ }^{2}$ S. S. SABLIN, ${ }^{2}$ R. TANNENBAUM, $^{3}$ \\ K. DAHMEN ${ }^{4}$ \\ ${ }^{1}$ Department of Mechanical Engineering, Florida A\&M University-Florida State University (FAMU-FSU) College of \\ Engineering, Tallahassee, Florida 32310 \\ ${ }^{2}$ School of Computational Science and Information Technology, Florida State University, Tallahassee, Florida, 32306 \\ ${ }^{3}$ School of Materials Science and Engineering, Georgia Institute of Technology, Atlanta, Georgia 30332 \\ ${ }^{4}$ Department of Chemistry and Biochemistry, Florida State University, Tallahassee, Florida 32306
}

Received 15 April 2003; revised 19 December 2003; accepted 19 December 2003

\begin{abstract}
The microstructure of an epoxy system oriented in high magnetic fields (15-25 T) has been observed to consist of highly oriented domains at the molecular level along the direction of the applied field. The changes in the microstructure have been characterized as a function of the magnetic-field strength and have been investigated microscopically and with wide-angle X-ray diffraction. The mechanical properties of the epoxy have been examined in light of nanoindentation experiments at different load levels. The basic results of the experimental investigations for the effect of high magnetic fields on the structure and property of the epoxy are presented. Nanoindentation testing has revealed large differences in the nanomechanical behavior for thermomagnetically processed epoxy specimens. The differences can be ascribed to the microstructural changes (reorientation) of the polymer at the molecular level. (C) 2004 Wiley Periodicals, Inc. J Polym Sci Part B: Polym Phys 42: 1586-1600, 2004
\end{abstract}

Keywords: curing of polymers; indentation; magnetic polymers; modulus; orientation; self-assembly; X-ray

\section{INTRODUCTION}

The need for high-strength materials for structural applications has driven the development of polymeric materials with a high degree of anisotropy at the molecular level. The ability to direct the local organization of polymer materials through the rational design of the chemical structure and processing methods is of continuing scientific and technological interest. One means of guiding the development of desirable microstruc-

\footnotetext{
Correspondence to: M. S. Al-Haik (E-mail: marwan@ mail.magnet.fsu.edu)

Journal of Polymer Science: Part B: Polymer Physics, Vol. 42, 1586-1600 (2004) (c) 2004 Wiley Periodicals, Inc.
}

tures is an externally applied field. The gradients in the thermodynamic potential may be chemical, mechanical, magnetic, or electrical in origin.

Long-range ordering of the polymer chain axes resulting in chain alignment can be induced by several methods, such as melt spinning, ${ }^{1}$ extrusion, ${ }^{2}$ and injection molding. ${ }^{3}$ Some of these techniques produce an oriented shell of the polymer with a relatively unoriented inner core. ${ }^{4,5}$ This uneven shell-core orientation can be attributed to different factors. For example, the morphologies produced through injection molding are governed by three major factors. They are the rheological and interfacial properties of the constituent components (e.g.,, shear viscosity, fluid elasticity, and interfacial tension), the blend composition, and 
the processing variables (e.g., temperature and shear rate). ${ }^{6}$ In a similar investigation, Quintana et $\mathrm{al}^{7}$ observed that the surfaces (skin) of injectionmolded specimens that cooled more rapidly during the injection molding exhibited markedly finer polymer domain structures than their inner parts (core) and the specimens prepared by compression molding, in which the separate coalescence of the polymer drops could proceed.

The orientation of polymer chains subjected to the influence of external electric fields has also been an area of extensive study. Electric fields are of use because of the degree of precision that can be exerted over the magnitude and dynamics of the field and the ability to create micromachined electrodes of well-defined size and shape. ${ }^{8}$ Controlling the orientation of organic molecules with electric fields plays an important role in commercially important devices, such as liquid-crystalline displays. Liquid-crystalline polymers exhibit dramatic alignment effects in electric fields. Korner et al. ${ }^{9}$ and Shiota and Ober ${ }^{10}$ created aligned samples of liquid-crystalline thermosets by curing in an alternating-current electric field. The structure evolution during curing was monitored by in situ X-ray diffraction. The orientation was found to be dependent on both the liquid-crystal nature of the thermosets and their dielectric anisotropy. The orientation was controlled through variations in the frequency of the alternating electric fields, and it was locked into a robust network structure by a crosslinking reaction that took place concurrently with orientation. The Korner investigation showed that reorientation could be introduced to a thermoset polymer by a small electric field of 1 $\mathrm{V} / \mu \mathrm{m}$ through a change from a high-frequency electric field $(>1000 \mathrm{~Hz})$ to a low-frequency one $(<50 \mathrm{~Hz})$. This change in frequencies caused a $90^{\circ}$ flip in the molecular orientation.

The magnetic-field-induced alignment of polymeric materials has been the focus of several research efforts. ${ }^{11-16}$ Polymeric materials can interact with a magnetic field through the diamagnetic anisotropy of the constituent chemical units. The energy that the chemical unit gains through the interaction with an external magnetic field is dependent on the orientation of the unit with respect to the magnetic field, and so the unit tends to align in a direction that would minimize its energy. ${ }^{15}$ The tendency of a unit to align is suppressed by the thermal agitation, if the energy reduction due to alignment cannot compensate for the energetic penalty that arises because of the expenditure of thermal energy. This is the case for non-liquid-crystalline polymers in melts and solutions. The application of a magnetic field has a significant effect on the orientation of liquid-crystalline materials through the interaction with molecules with diamagnetic anisotropy. Polymer molecules tend to align with their chain axes parallel to a magnetic field, especially when the randomizing effect of thermal energy is reduced by the orientation of the molecules within a mesophase. $^{16}$

The magnetic orientation of various polymers has been measured with X-ray diffraction,, ,11,15 magnetic birefringence, ${ }^{14}$ and nuclear magnetic resonance ${ }^{17}$ and through the study of the effect of such orientation on their microstructure. ${ }^{11,16,18,19}$ The application of a magnetic field during polymer processing produces enhanced mechanical and physical properties with respect to mechanical stretching. For example, when a magnetic field was applied during the cure reaction of a liquid-crystalline epoxy, ${ }^{5,11}$ the molecules aligned along the direction of the applied field. Measurements of the orientation parameter of the fully cured material by wide-angle X-ray scattering (WAXS) showed that the orientation improved with an increase in the field strength. The orientation parameters attained a maximum level at a field strength of approximately $12 \mathrm{~T}$. The elastic tensile modulus increased with the square of the orientation parameter, attaining a maximum value of $8.1 \mathrm{GPa}$ (cf. 3.1 GPa for the unoriented material). In a similar study, Manko et al. ${ }^{20}$ investigated the effect of weak magnetic fields on the properties of Kevlar Aramid fiber reinforced epoxy plastics. The greatest effect of hardening was achieved at a magnetic-field intensity of 9.6 $\mathrm{kA} / \mathrm{m}$, at which the ultimate strength increased by $23 \%$ and Young's modulus increased by $30 \%$.

The characterization of polymeric materials on a submicrometer scale is necessary for evaluating their performance in a wide variety of applications. Furthermore, the nanoscale properties that control the various aspects of material performance can be different from the bulk properties because of differences in the local chemistry or microstructure. ${ }^{21}$ Several testing standards can be used to characterize the mechanical properties of polymers, such as uniaxial tensile testing and dynamic mechanical analysis (DMA). However, to detect the effects of magnetic processing, special instruments are used to obtain high-sensitivity force and displacement measurements. Nanoindentation has emerged as a reliable technique for measuring the mechanical properties of both bulk 
and thin-film samples. ${ }^{22-24}$ However, despite the insight that this technique can provide, far fewer studies of the nanoscale indentation of polymeric materials have been reported, presumably because of the time-dependent mechanical behavior, which can complicate the interpretation of the results. Briscoe et al. ${ }^{25}$ showed recently that with newer data analysis methods such as that proposed by Oliver and Pharr, ${ }^{26}$ it is possible to obtain reliable values of the modulus and hardness. Drechsler et al. ${ }^{27}$ used nanoindentation with scanning force microscopy to evaluate Young's moduli of polycarbonate/poly(methyl methacrylate) (PMMA) blends. They showed that it is possible to evaluate polymeric material constants such as stiffness and viscosity with high local resolution. Brun et al. ${ }^{28}$ determined the mechanical properties of polypropylene by nanoindentation tests. This allowed them to estimate the hardness and Young's modulus for various penetration depths. Nanoindentation and nanoscratch testing of uniaxially and biaxially drawn poly(ethylene terephthalate) film were carried out by Beake and Leggett. ${ }^{29}$ These tests were used to correlate the effect of the difference in the processing history to the changes in the elastic modulus, hardness, and wear resistance. In the study carried out by Amitay-Sadovsky et al., ${ }^{30}$ the surface nanomechanical properties and morphology of thick polyurethane films were investigated with nanoindentation experiments performed at very low loads and small penetration depths. This investigation demonstrated that the elastic behavior of the polyurethane surface could be remarkably different from that of the bulk material. The distinctly different mechanical response to an applied pressure between the surface and nearsurface bulk regions of the polymer was attributed to the packing of the polymer chains at the contact region. Van Landingham et al. ${ }^{31}$ discussed the effects of viscoelasticity in polymer nanoindentation experiments and suggested different calibration procedures to account for the viscoelastic polymer behavior. In a parallel investigation, the effects of the maximum load and loading rate on nanoindentation experiments for several polymers were studied by Klapperich et al. $^{32}$

In this study, the microstructure evolution due to the magnetic processing of an epoxy system was evaluated with electron microscopy and wideangle X-ray diffraction (WAXD). The mechanical behavior of the magnetically processed epoxy was investigated with the nanoindentation technique.
Table 1. Physical and Mechanical Properties of the Epoxy System

\begin{tabular}{lcc}
\hline & $\begin{array}{c}\text { PH2032 (Epoxy } \\
\text { Resin Base) }\end{array}$ & $\begin{array}{c}\text { PH3660 } \\
\text { (Curing Agent) }\end{array}$ \\
\hline Viscosity & $90 \mathrm{~N} \mathrm{~s} / \mathrm{m}^{2}$ & $95 \mathrm{~N} \mathrm{~s} / \mathrm{m}^{2}$ \\
Mix ratio by & 100 & 27 \\
$\quad$ weight & $1.109 \mathrm{~kg} / \mathrm{L}$ \\
Density of the mix & $91.11^{\circ} \mathrm{C}$ \\
Glass-transition & \multicolumn{2}{c}{$50-60 \mathrm{~min}$} \\
$\quad$ temperature & $-\quad 67.76 \mathrm{MPa}$ \\
Pot life (4 oz) & $2.885 \mathrm{GPa}$ \\
Tensile strength & \multicolumn{2}{c}{} \\
Tensile modulus & \multicolumn{2}{c}{5} \\
\hline
\end{tabular}

The unloading data of the epoxy response were used to determine the surface nanomechanical properties, such as the elastic modulus and hardness. The results are discussed in the context of microstructural changes induced by the application of high magnetic fields during the curing of the epoxy.

\section{EXPERIMENTAL}

\section{Materials and Processing}

Aeropoxy was used as the matrix. It is a mediumviscosity, unfilled, light amber laminating resin designed for structural production applications. According to the specifications furnished by the manufacturer (PTM\&W Industries, Inc.), the components of the epoxy used here are Aeropoxy PR2032, a material containing diphenylolpropane (bisphenol A), and a multifunctional acrylate; the hardener component Aeropoxy PH3660 is a modified amine mixture. The epoxy also contains some acrylic monomers. These materials do not contain metallic compounds of any kind. The absence of metallic compounds in the epoxy resin eliminates the possibility of metallic-compoundinduced orientation of the polymer bundles, and this attributes the response to the magnetic field to the polymer network itself.

This resin laminates very easily and wets out fiberglass, carbon, and Kevlar Aramid fibers readily. Used with the PH3660 hardener, this system cures at room temperature for $24 \mathrm{~h}$. The typical properties of this epoxy are listed in Table 1.

The components were mixed mechanically by sonication for $10 \mathrm{~min}$. The mix ratio for each 
sample was 4:1 (w/w). The epoxy system was degassed moderately until no gas bubbles could be seen, and then it was injected separately, with $10-\mathrm{mm}$ syringes, inside quarts tubes $8 \mathrm{~mm}$ in diameter and $50 \mathrm{~mm}$ long. The quartz tubes were sealed and wrapped around a sample holder with nonmagnetic tape.

The magnetic processing of the samples was carried out at the National High Magnetic Field Laboratory (Tallahassee, FL). The magnetic fields were generated by a 25 -T direct-current (DC) resistive solenoid. This magnet has a large bore so it can accommodate a furnace. The temperature inside the furnace is provided by a heating element and is measured by a Pt thermocouple, which has low magnetic properties. A proportional-integralderivative (PID) controller controlled the temperature.

Once the sample holder was placed inside the furnace, the furnace was pushed into the magnet bore so that the samples were in the center of the magnetic field, and subsequently, the magnet was brought up to a 25-T field. The samples were left to cure at room temperature inside the field for $2 \mathrm{~h}$ with no applied heat so that the viscosity remained as low as possible. Then, the furnace was heated to $60{ }^{\circ} \mathrm{C}$, and the samples were left to cure under the magnetic field for another $2 \mathrm{~h}$. After this, the magnetic field was reduced to $0 \mathrm{~T}$, and the samples were placed in another furnace at $60{ }^{\circ} \mathrm{C}$ for another $2 \mathrm{~h}$ to fully cure. The experiment was repeated at a 15 -T field with the same magnetic processing and curing cycles. One reason for this two-stage cycle was that we conducted a parallel investigation, trying to align carbon nanotubes inside the epoxy matrix under a high magnetic field. The composite was left to cure at room temperature for $2 \mathrm{~h}$ so that the viscosity remained as low as possible. Keeping the viscosity low was expected to allow the carbon nanotubes to move easily in the resin medium. The next curing step at $60{ }^{\circ} \mathrm{C}$ was to lock the movement of the nanotubes, under the assumption that alignment had occurred. We demonstrated the alignment of the carbon nanotubes. ${ }^{33,34}$

\section{Polymer Orientation Analysis}

Fracture surface samples were obtained by the cleavage of the samples after they were notched with a razor blade. The fracture surfaces were cut parallel to the magnetic-field direction. The fracture surfaces were examined with an Electroscan model E-3 environmental scanning electron microscopy (ESEM) facility.

We obtained polished sections of the processed samples by sectioning parallel to the magneticfield direction and by using a Philips X'Pert PW3040 MRD X-ray diffractometer equipped with a pole figure goniometer with Ni-filtered $\mathrm{Cu} \mathrm{K} \alpha$ radiation. The accelerating voltage was $50 \mathrm{kV}$, and the tube current was $40 \mathrm{~mA}$. The $2 \theta$ scan data were collected from $2 \theta=1^{\circ}$ to $2 \theta=30^{\circ}$ in $0.01^{\circ}$ steps for a period of $1 \mathrm{~s}$ per step. A series of radial scans were obtained at various azimuthal angles $(\phi)$ through the rotation of each sample on its own plane between $\phi=0^{\circ}$ and $\phi=360^{\circ}$. The $\phi$ scans were performed in $0.1^{\circ}$ steps for a period of $0.5 \mathrm{~s}$ per step. A schematic of the X-ray sample holder is shown in Figure 1.

Incomplete pole figures were obtained with $\theta$ varying from 0 to $85^{\circ}$ in $5^{\circ}$ intervals and $\phi$ varying from 0 to $360^{\circ}$ in $5^{\circ}$ steps. Obtained raw pole figures were further normalized as follows:

$$
\oint P_{h_{i}}(y) d y=4 \pi
$$

where function $P(y)$ is the volume fraction of the sample for which the lattice plane normal $h$ is parallel to the sample direction $y$.

\section{Characterization By Nanoindentation}

The distinguishing features of most nanoindentation tests are that the penetration depth scale and the area of contact between the indenter and the specimen are measured indirectly instead of the area being calculated from the residual impression left in the specimen surface upon the removal of the load. ${ }^{35-38}$ The measurements of the elastic modulus and hardness by load-displacement sensing indentation techniques ${ }^{26}$ are made with a Berkovich indenter, which is a sharp, triangular pyramid made out of diamond. The key data needed for the analyses are the peak load $\left(P_{\max }\right)$, the displacement at the peak load $\left(h_{\text {max }}\right)$, and the initial unloading constant stiffness $(S)$, that is, the slope of the initial portion of the unloading curve.

The effective modulus $\left(E_{\text {eff }}\right)$ can be related to the stiffness by the following expression: ${ }^{39}$

$$
S=\frac{2}{\sqrt{\pi}} E_{\text {eff }} \sqrt{A}
$$

where $A$ is the projected area of the indenter (for the Berkovitch indenter, it has been calculated to 


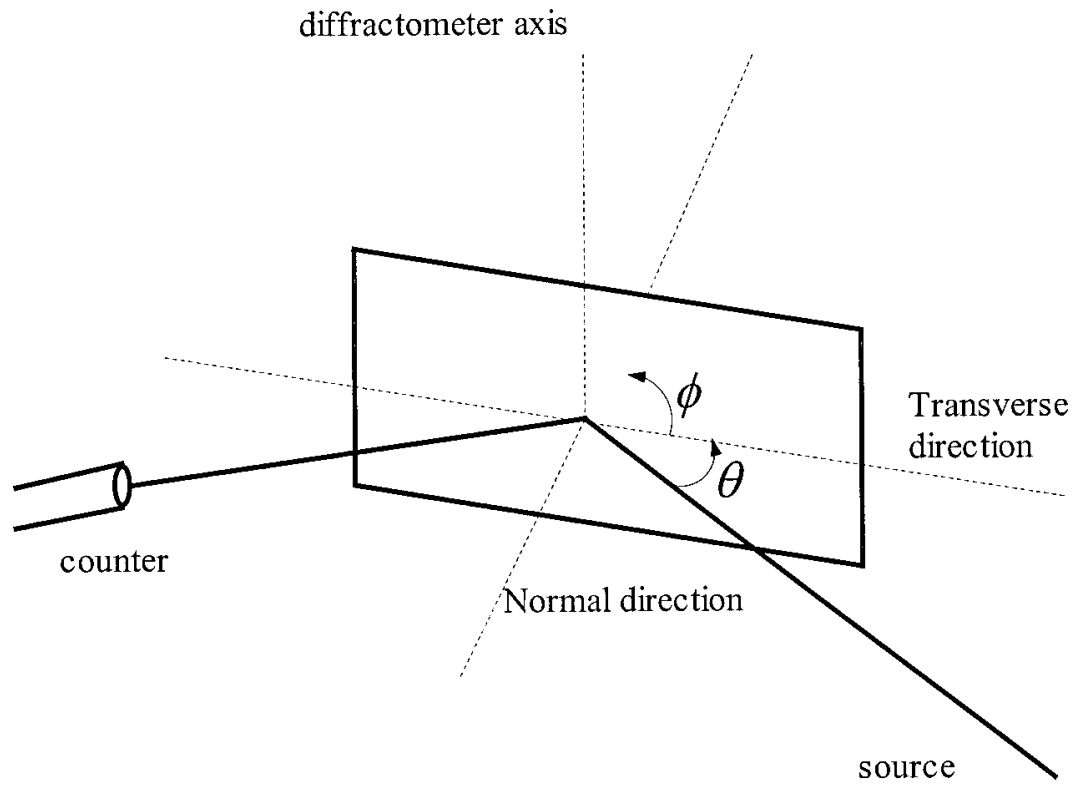

Figure 1. Setup for the WAXD experiments.

be $24.5 h_{s}{ }^{2},{ }^{39}$ where $h_{s}$ is the intercept of $S$ at zero load). The contact depth $\left(h_{\mathrm{c}}\right)$ is calculated as follows:

$$
h_{\mathrm{c}}=h_{\max }-\varepsilon \frac{P_{\max }}{S}
$$

$\epsilon$ is 0.75 for a Berkovitch indenter. Because the indenter is never a perfectly shaped pyramid, a tip-shape correction and a compliance of the indenter frame have to be applied to the analysis, and this results in the following expression for the true stiffness of the contact $\left(S_{\text {real }}\right)$ :

$$
S_{\text {real }}=\frac{1}{\frac{1}{S}-C_{\mathrm{f}}}
$$

where $C_{\mathrm{f}}$ is the frame compliance. $E_{\text {eff }}$ is hence given by

$$
E_{\text {eff }}=\left(\frac{\sqrt{\pi}}{2}\right)\left(\frac{1}{\sqrt{A\left(h_{\mathrm{c}}\right)}}\right)\left(\frac{1}{C-C_{\mathrm{f}}}\right)
$$

where $C$ is the measured compliance, defined as the inverse of $S$.

A nanohardness tester, with a diamond Berkovitch indenter, manufactured by CSM Co., was used to indent both the reference sample and the processed epoxy samples. The displacement and force resolutions of this instrument were $0.04 \mathrm{~nm}$ and $1 \mu \mathrm{N}$, respectively.

To clean the indenter tip, we made several indentations at different load levels on a flat copper sample. The reference sample was standard fused quartz supplied by CSM (Young's Modulus, $E=72 \mathrm{GPa}$ ). Fused quartz is an isotropic material used as a calibration standard by the nanoindentation community because its hardness and elastic modulus do not vary significantly with the indentation depth. The experiments for the calibration sample consisted of arrays of 40 indentations, each array spanning eight different loads $(0.5,0.7,1.0,1.2,1.5,10,40$, and $100 \mathrm{mN}) \mathrm{re}-$ peated five times per load. The data from each of the five indentations made to the same load were analyzed. The loading rates used for each load level were 1.00, 1.4, 2.00, 2.4,3.0, 20, 80, and 200 $\mathrm{mN} / \mathrm{min}$, respectively. Representative unloading curves for the calibration sample are shown in Figure 2.

The epoxy samples were prepared by successive grinding steps with sand paper down to 200 grits and by polishing steps with $1-\mu \mathrm{m}$ diamond paste on nylon cloth.

The tip was calibrated according to the results of the reference material and was cleaned with isopropyl alcohol before each indentation set for the epoxy samples. The set of indentations of all 


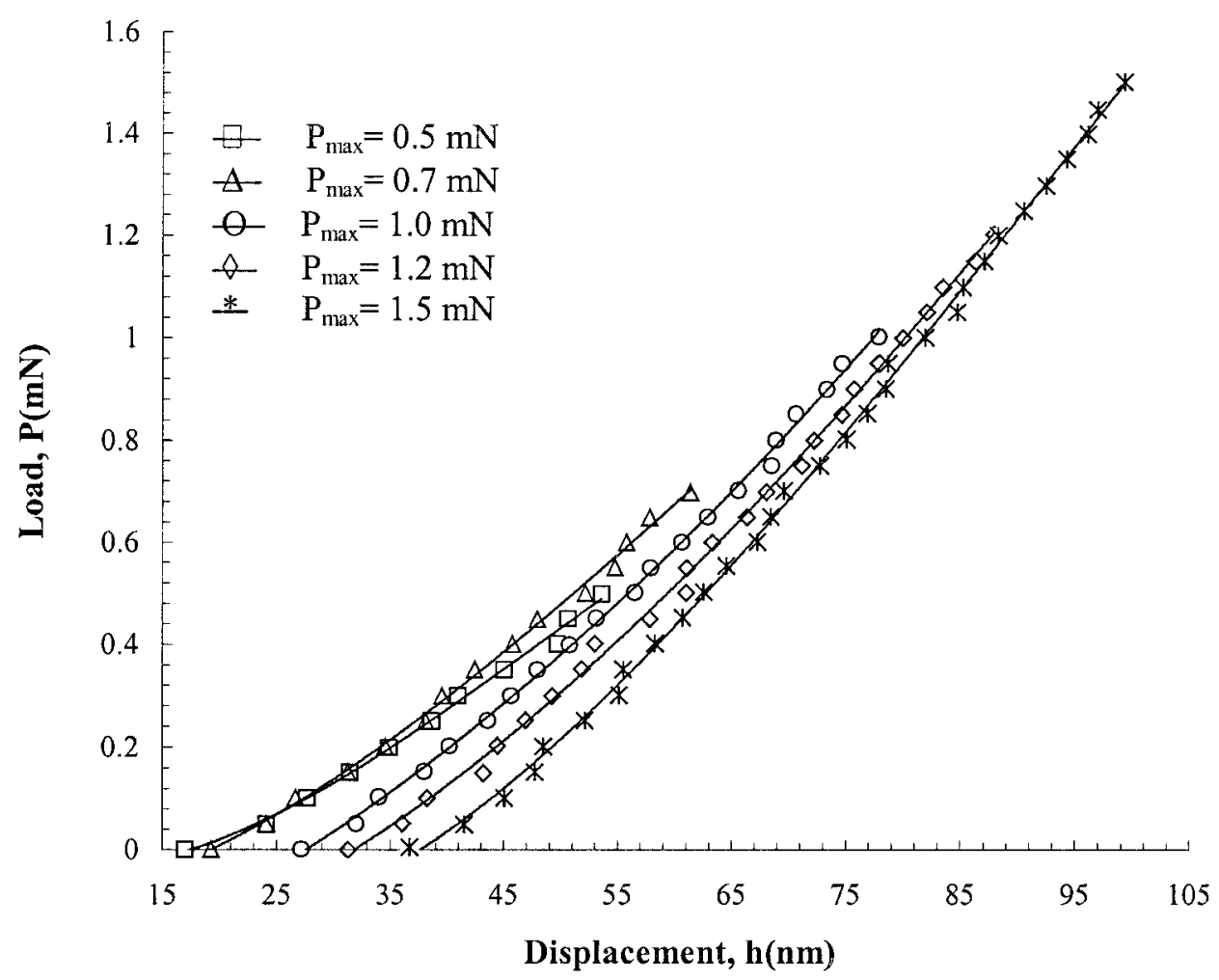

Figure 2. Unloading portion of the nanoindentation load-displacement data for fused silica obtained with a Berkovitch indenter. Loading and unloading were carried out for different load levels and at different loading rates.

the three epoxy samples were performed for a range of maximum loads between 300 and 1000 $\mu \mathrm{N}$ at a constant loading/unloading rate of 1.8 $\mathrm{mN} / \mathrm{min}$.

\section{RESULTS AND DISCUSSION}

In this study, the epoxy cured without a magnetic field is labeled 0T; the epoxy cured under $15 \mathrm{~T}$ is labeled $15 \mathrm{~T}$, and the sample cured under a $25-\mathrm{T}$ field is $25 \mathrm{~T}$.

\section{Microstructure Results}

The microstructures of the magnetically untreated and magnetically processed samples were examined with ESEM. We prepared fracture surfaces by fracturing across the alignment direction on planes parallel to the magnetic-field orientation. The micrographs of the fracture surface of the epoxy samples are presented in Figure 3.

Figure 3(a) shows a micrograph of the fracture surface of a sample processed outside the mag- netic field, exhibiting no preferred orientation of the polymer. The application of the 15-T magnetic field led to the development of domains within which the chains of the epoxy were oriented in the direction of the field. The morphology of the epoxy processed in the presence of the magnetic field consisted of the formation of fibrils, as shown in Figure 3(b). In a sample processed under a 25-T magnetic field [Fig. 3(c)], the fibrils were more uniform along the direction of the magnetic field, and all domains, including the boundary, showed a common orientation, aligning efficiently with the field. It is clear that the preferred orientation induced by the 15- and 25-T fields is very apparent in the fracture surfaces of samples. The preferred orientations induced by the 15- and 25-T fields are very apparent in the fracture behavior of the samples, which is fissile on planes parallel to the magnetic-field axis, as shown in Figure $3(\mathrm{~b}, \mathrm{c})$, respectively.

\section{WAXD Results}

It is commonly understood that amorphous chain segments can have some long-range order. WAXD 


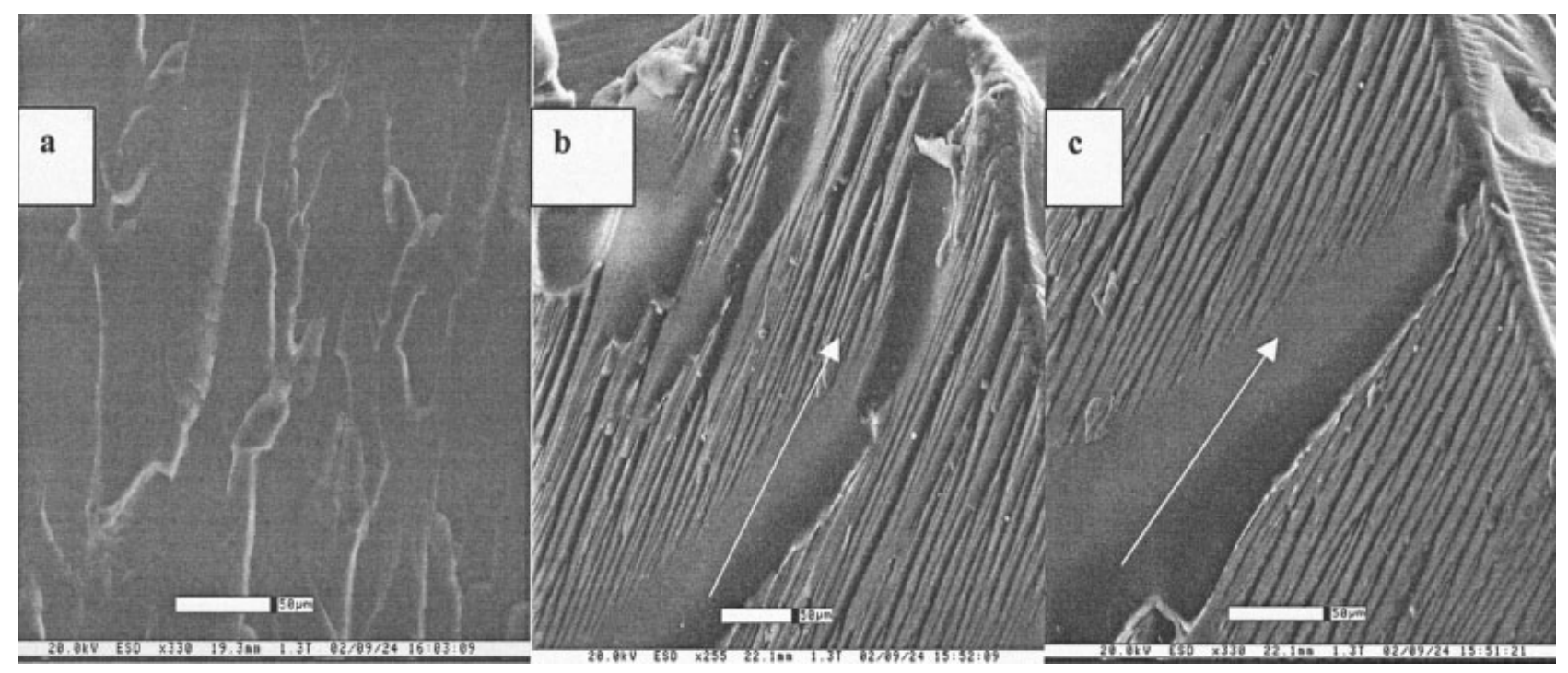

Figure 3. ESEM micrographs for the morphology of the fracture surface for magnetically processed epoxy samples at (a) 0 , (b) 15, and (c) $25 \mathrm{~T}$. All the samples were processed with the same curing schedule: $2 \mathrm{~h}$ at $25{ }^{\circ} \mathrm{C}$ and $4 \mathrm{~h}$ at $60{ }^{\circ} \mathrm{C}$. The arrows represent the direction of the corresponding applied magnetic field.
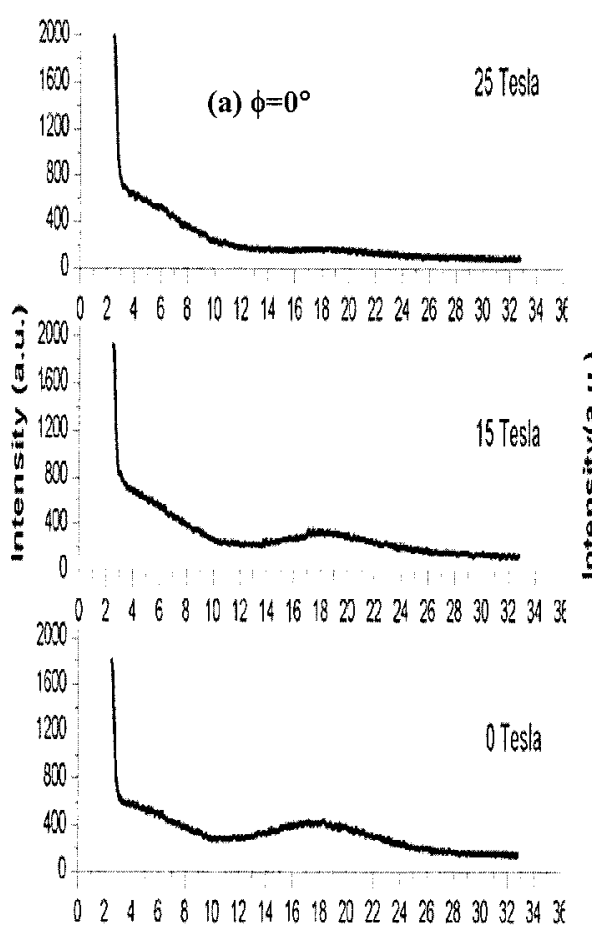

20

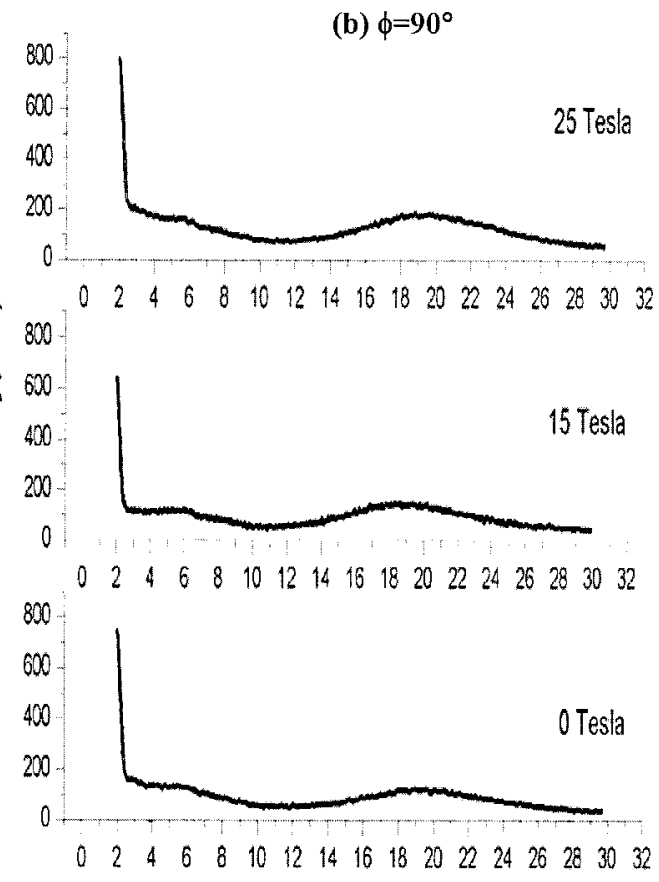

20

Figure 4. $2 \theta$ diffraction for the 0 -, 15-, and 25-T cured epoxy samples: (a) $\phi=0^{\circ}$, normal to the magnetic-field direction, and (b) $\phi=90^{\circ}$, parallel to the magnetic-field direction. 
is used for the conformation analysis of amorphous chain segment ordering. The $2 \theta$ scans for three different epoxy samples at $\phi=0^{\circ}$ are shown at Figure 4(a). There are no significant peaks that can be attributed to crystalline phase; only a weak and diffuse amorphous halo exists. The degree of crystallinity of the epoxy resin is very low. Most of the macromolecules are in an amorphous region. The analysis of this halo can provide information concerning the structure of the amorphous regions. The position of the halo is at $2 \theta$ $=19^{\circ}$, corresponding to a period distance of $4.7 \AA$, which is related to the average interchain distance in the amorphous component. The decrease in the intensity of the peak as the magnetic-field strength increases is clear in Figure 4(b), and it indicates that the magnetic field minimized the orientation density along the transverse direction (TD) of the samples at $\phi=0^{\circ}$. For $\phi=90^{\circ}$, the diffraction scans give information about the amorphous chain orientation along the axis of the sample that was parallel to the applied magnetic field. The results of the scan along the sample axis suggest that the magnetic field forced the amorphous phase to reorient along the magneticfield direction; this reorientation is more pronounced at $2 \theta=19^{\circ}$. This is most likely due to a two-dimensional stretching effect that is generated in the crosslinked epoxy network, which locks in a polymer configuration in which an energetic equilibrium is reached between the interaction of the magnetic field with the polymer chains and the drag forces on the polymer chains (due to increasing viscosity) that inhibit polymer chain movement.

The change in the intensity of the amorphous peak signifies that the amorphous chains segments reoriented parallel to the sample axis are more densely packed than those that are either randomly oriented or oriented perpendicularly to the sample axis. The peak of the amorphous halo increases proportionally to the increment in the magnetic-field strength. To study the alignment of the amorphous phase, we measured comprehensive azimuthal scans by fixing the $2 \theta$ value at $19^{\circ}$ and varying $\phi$ in the range of $0^{\circ} \leq \phi<360^{\circ}$ for each magnetically processed sample, as shown at Figure 5. It is clear that all three $\phi$ scans contain a set of two peaks and that the peaks in all the scans are located at the same angles, around $\phi=90^{\circ}$ and $\phi=270^{\circ}$, with a separation of $80^{\circ}$. The obvious features of the azimuthal intensity scans of the amorphous diffraction is the increase in the halo intensity with the strengthen- ing of the magnetic field and the narrowing of the width of the peak. The full width at half-maximum (fwhm) of sample 0T was $89^{\circ}$, and it decreased significantly under the magnetic field: $61^{\circ}$ for sample $15 \mathrm{~T}$ and $56^{\circ}$ for sample $25 \mathrm{~T}$. There was only a small reduction in the values of fwhm upon the increase in the magnetic field from 15 to $25 \mathrm{~T}$. This was due to the fact that increasing the magnetic field from 15 to $25 \mathrm{~T}$ produced a slightly higher degree of orientation along the magnetization direction (MD) during curing. This confirms the reorientation of the amorphous chains along the axial direction of a sample parallel to the applied magnetic field.

The sample cured at $0 \mathrm{~T}$ was not fully random in texture. This initial residual orientation may have been due to the injection effect when the mixture was injected into the quart tubes. Gravity could also contribute a little to the weak texture. It is well known that the processing methods in fabrication will introduce this effect. For this epoxy system, we applied the same fabrication process, except for the change in the magnetic field, to study the effect of the magnetic field on the orientation during curing. What is important is the degree of randomness, which is a measure of orientation. The sample cured at $0 \mathrm{~T}$ had a texture intensity of approximately 3 times random. This is a fairly common texture intensity for samples processed under equivalent conditions. This increased to approximately 8 times random for the samples cured in the field. This is a significant increase in the texture intensity. The separation of the peaks in the azimuthal scans shows that the change in texture was also qualitative and indicates a consistent change in the nature of the texturing for these materials.

The aforementioned in-plane orientation relationships are in good agreement with a previous study of epoxy resin systems cured under magnetic fields, ${ }^{5,11}$ in which it was found that the presence of the magnetic field during the cure reaction aligned the molecules along the applied field. Orientation parameters obtained from WAXS pattern showed that the orientation obtained a maximum level at a field strength of approximately $12 \mathrm{~T}$. In this study, the $\phi$ scans showed that the molecules oriented along the magnetic direction and that the stronger magnetic field introduced the highest degree of orientation at a field strength of $25 \mathrm{~T}$.

To further understand the orientation of the molecules in an epoxy resin, we constructed pole figures at $2 \theta=19^{\circ}$ of these three samples. A pole 


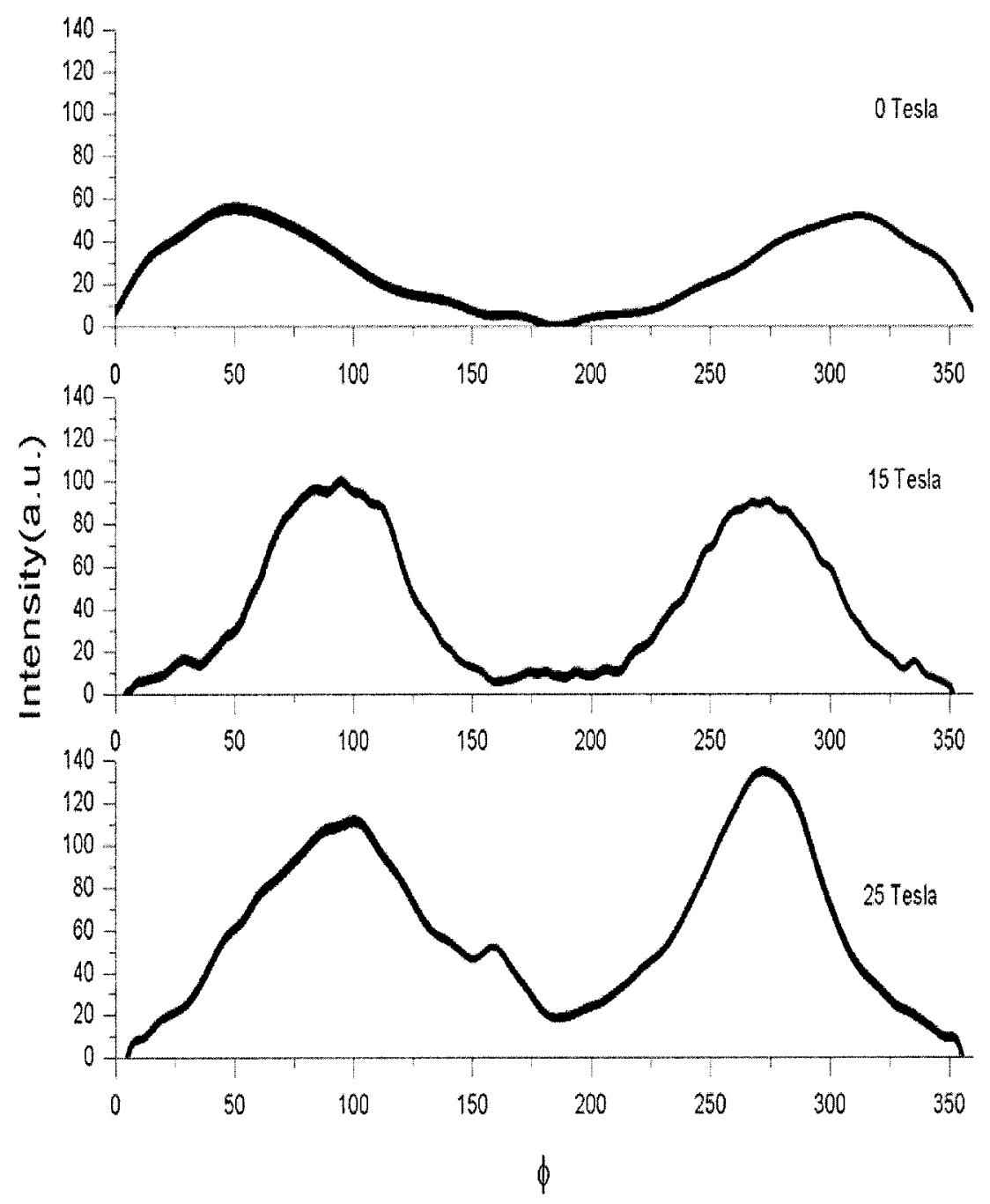

Figure 5. Azimuthal $(\phi)$ scans of the diffraction intensity for different magnetically processed epoxy samples. All scans were carried out at $2 \theta=19^{\circ}$.

figure may represent not only the orientation of the crystalline component of a polymer ${ }^{40,41}$ but also the orientation of the amorphous component. ${ }^{42}$ Figure 6 shows the normalized raw pole densities plotted in units of a time random distribution in which 1 corresponds to complete random orientation distribution. In these graphs, the intersection of the crosshairs corresponds to the normal direction (ND; see Fig. 1, which gives the sample direction). The maximum pole intensity in sample $0 \mathrm{~T}$ is 4.2 time random units, which is very low compared to that of 8.6 time random units in sample $15 \mathrm{~T}$ and 9.5 time random units in sample $25 \mathrm{~T}$. In the absence of a magnetic field, the cured sample was isotropic. The maximum orientation of the molecules was along the ND. Under the magnetic field, the maximum of the intensity in- creased, and the texture components were still on the ND-MD plane. With the increase in the magnetic-field strength, the texture component moved toward the MD. In sample 0T, the texture component with the highest intensity was around ND. In sample $15 \mathrm{~T}$, the texture component was tilted $15^{\circ}$ from the ND toward the MD. In sample 25T, the component was $35^{\circ}$ from the ND toward the MD. It is clear from the established pole figures that with the increase in the magnetic-field strength, more molecules were oriented toward the MD direction.

\section{Nanoindentation Results}

Table 2 shows the data used for the constantmodulus tip-shape correction collected from the 


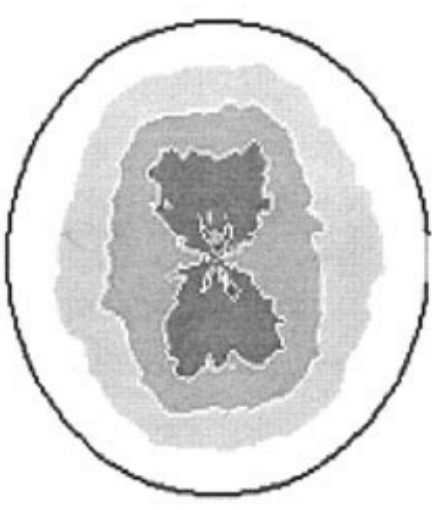

(a)

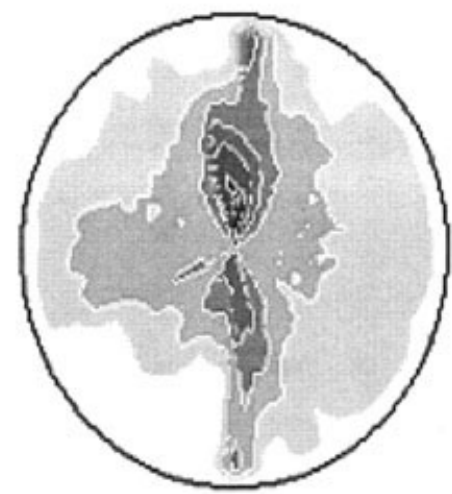

(b)

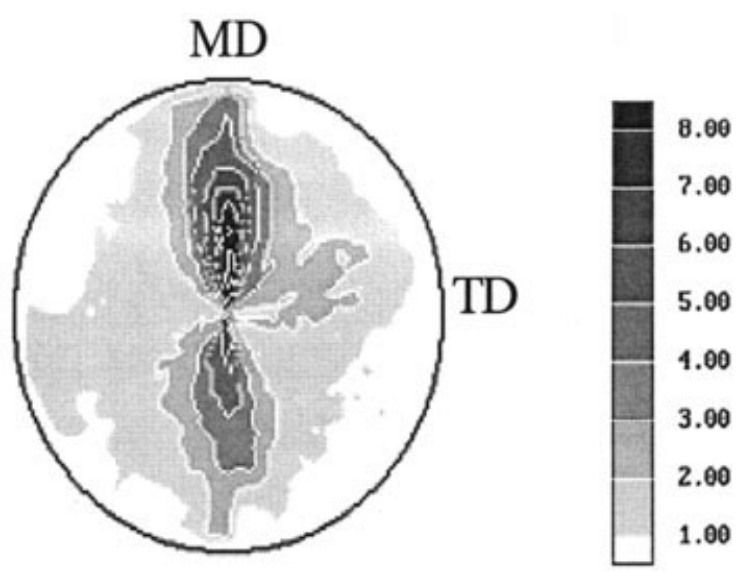

(c)

Figure 6. Pole figures of (a) 0-, (b) 15-, and (c) 25-T magnetically processed epoxy samples. The normalized raw pole densities are plotted in units of the time random distribution; 1 corresponds to a complete random orientation distribution.

reference sample. Only the range of $95-40 \%$ of the unloading portion was considered for obtaining $S$ to minimize the viscoelastic behavior due to creep-related artifacts commencing at the onset of unloading. ${ }^{31,32}$ The initial unloading slope (stiffness $S$ ) was then found by analytical differentiation of the power law and by the evaluation of the derivative at the peak load and displacement. The averaged values of $m$ and $B$ (see the detailed precalculation procedure in ref. 26) were 1.243 and $0.04739 \mathrm{mN} / \mathrm{nm}$, respectively; this agreed well with the values cited in ref. 26 . The stiffness value was then implemented in the appropriate expression to calculate $h_{\mathrm{c}}$.

Table 2. Mechanical Properties for the Reference Sample (Fused Silica) Calculated with ConstantModulus Tip-Shape Correction

\begin{tabular}{ccccc}
\hline $\begin{array}{c}P_{\max } \\
(\mathrm{mN})\end{array}$ & $\begin{array}{c}h_{\max } \\
(\mathrm{nm})\end{array}$ & $\begin{array}{c}h_{\mathrm{c}} \\
(\mathrm{nm})\end{array}$ & $\begin{array}{c}E^{*} \\
(\mathrm{GPa})\end{array}$ & $\begin{array}{c}H \\
(\mathrm{GPa})\end{array}$ \\
\hline 0.5 & 53.59 & 30.86 & 74.48 & 12.99 \\
0.7 & 61.37 & 34.03 & 73.05 & 12.23 \\
1.0 & 77.89 & 46.63 & 71.20 & 11.17 \\
1.2 & 87.89 & 52.79 & 71.32 & 11.77 \\
1.5 & 99.30 & 61.41 & 72.35 & 12.26 \\
10 & 288.86 & 192.20 & 71.60 & 10.78 \\
40 & 592.60 & 402.07 & 72.19 & 10.13 \\
100 & 951.35 & 650.78 & 72.08 & 9.68 \\
\hline
\end{tabular}

$E^{*}$ : Indentation Modulus. $H$ : Hardness.
To find the area function and the load frame compliance, we obtained initial estimates of the machine compliance $C_{\mathrm{f}}$ and the apparent modulus by plotting $C$ versus $A^{-1 / 2}$ for the two largest indentations ( 40 and $100 \mathrm{mN}$ ). With these values, contact areas were computed for all eight indentations loads, from which an initial guess of the area function $A\left(h_{\mathrm{c}}\right)$ could be obtained. Because the exact form of the area function influenced the values of $C_{\mathrm{f}}$ and $E_{\text {eff }}$, the procedure was repeated several times until convergence was achieved. Figure 7 shows a plot of the final values of $C-C_{\mathrm{f}}$ versus $A^{1 / 2}$. The data are linear and extrapolate to $C-C_{\mathrm{f}}=0$, as expected when the appropriate machine compliance and area function are achieved. The calculated value of $C_{\mathrm{f}}$ upon convergence was $0.7105 \mathrm{~nm} / \mathrm{mN}$.

The results for the calibration of the fused quartz sample are tabulated in Table 2.

The Young's modulus values of the reference material are very close to the standard value of 72 $\mathrm{GPa}$, especially for maximum applied load values over greater than $.5 \mathrm{mN}$.

Figures 8 and 9 show the corresponding loading-unloading cycle data for the three epoxy samples at two different maximum load levels. The data were obtained at a constant loading/unloading rate of $1.8 \mathrm{mN} / \mathrm{min}$. The maximum displacement was in the range of $460-660 \mathrm{~nm}$, as shown in Figure 8. The nanoindentation of the epoxy shows that the sample processed inside a 25-T field had the minimum penetration depth in com- 


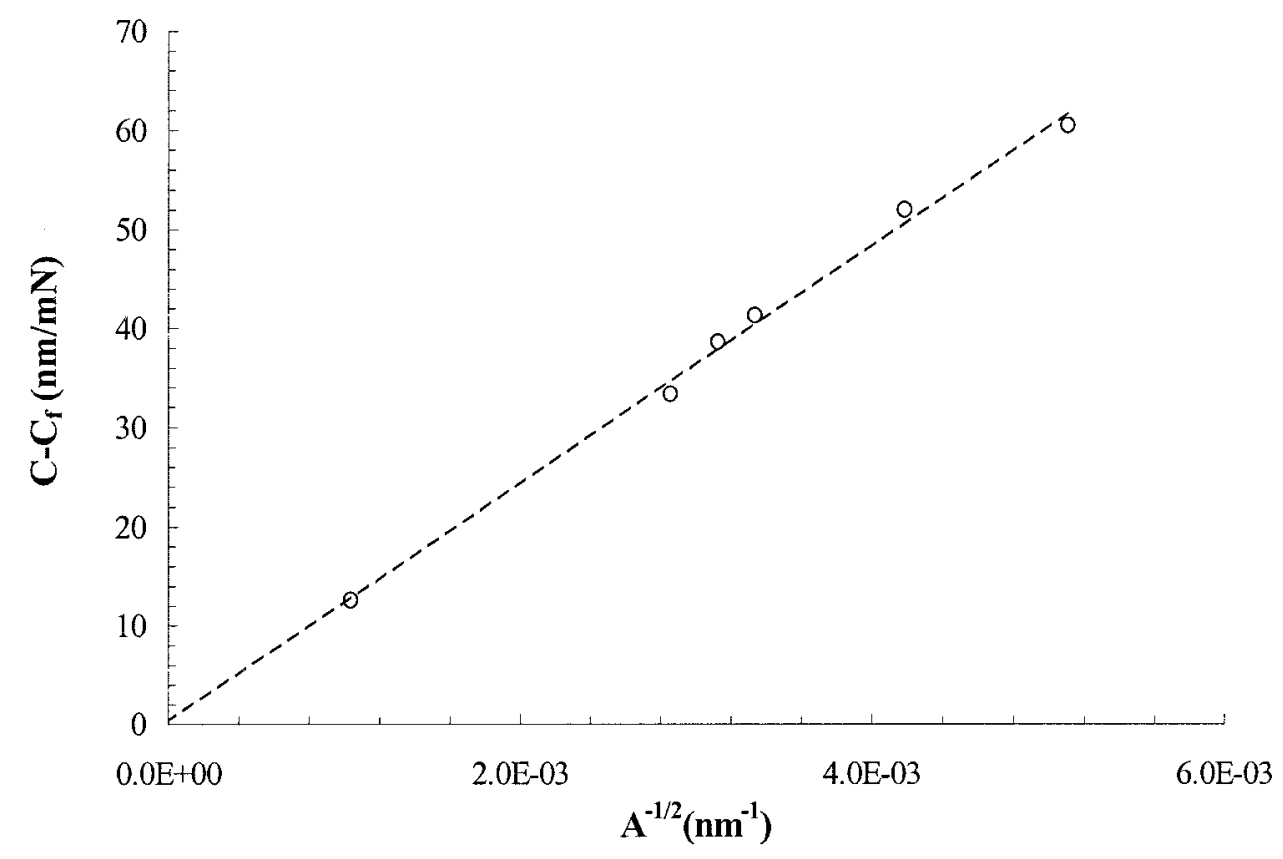

Figure 7. Plot of the actual compliance $\left(C-C_{\mathrm{f}}\right)$ versus $A^{-1 / 2}$ for a fused silica reference sample. The data have been corrected to account for machine compliance and area function corrections.

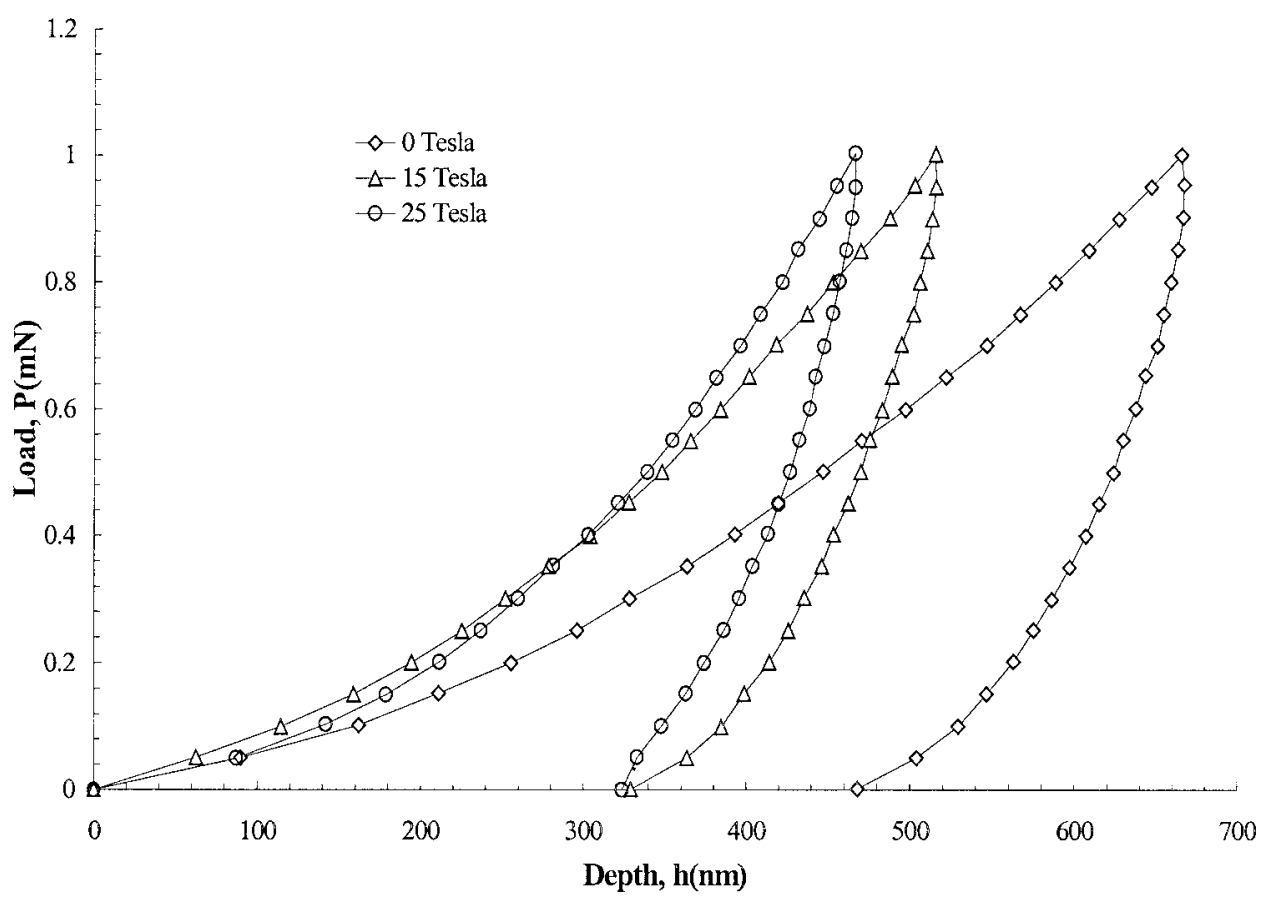

Figure 8. Representative load-displacement curves corresponding to each of the magnetically processed epoxy samples. The maximum load applied was $1 \mathrm{mN}$, and the loading/unloading rate was $1.80 \mathrm{mN} / \mathrm{min}$. 


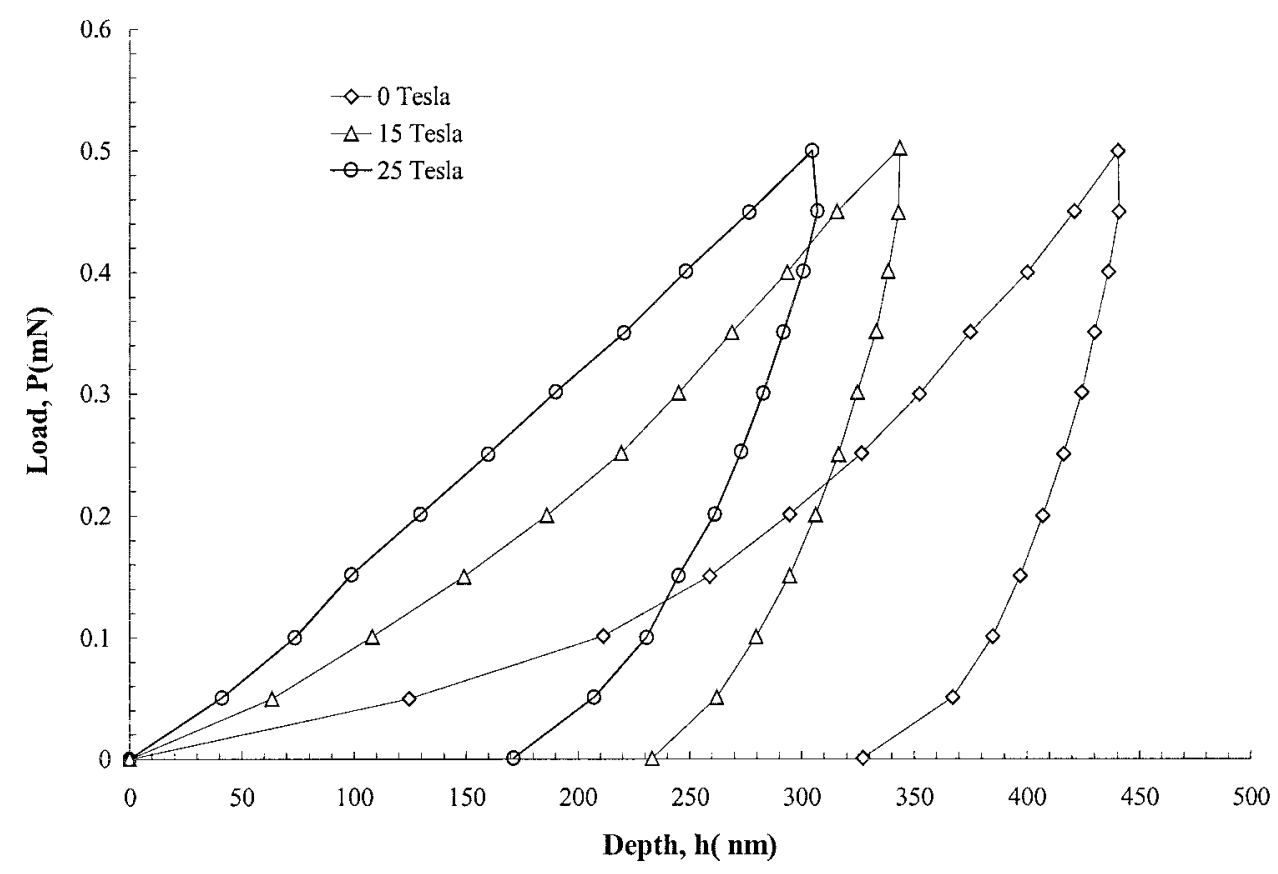

Figure 9. Representative load-displacement curves corresponding to each of the magnetically processed epoxy samples. The maximum load applied was $500 \mu \mathrm{N}$, and the loading/unloading rate was $1.80 \mathrm{mN} / \mathrm{min}$.

parison with the 15- and 0-T samples. With the area function obtained from the fused quartz sample together with the machine frame compliance, the apparent moduli and hardness for the epoxy samples were calculated, and they are given in Table 3 . The tabulated values of the modulus and hardness represent the averages of five different experiments.
The calculated modulus and hardness were consistent for each sample, with an increasing trend for the Young's modulus values with a decreasing penetration depth for all the epoxy samples.

Comparing the results reveals that the samples processed inside a magnetic field became harder and stronger than those processed in the

Table 3. Mechanical Properties of the Epoxy Samples Processed at Different Magnetic Fields

\begin{tabular}{cccccccc}
\hline $\begin{array}{c}\text { Field } \\
\text { (Tesla) }\end{array}$ & $\begin{array}{c}P_{\text {max }} \\
(\mathrm{mN})\end{array}$ & $\begin{array}{c}h_{\text {max }} \\
(\mathrm{nm})\end{array}$ & $\begin{array}{c}h_{\mathrm{c}} \\
(\mathrm{nm})\end{array}$ & $\begin{array}{c}h_{\mathrm{f}} \\
(\mathrm{nm})\end{array}$ & $\begin{array}{c}A\left(h_{\mathrm{c}}\right) \\
(\mathrm{nm})^{2}\end{array}$ & $\begin{array}{c}H \\
(\mathrm{GPa})\end{array}$ & $\begin{array}{c}E \\
(\mathrm{GPa})\end{array}$ \\
\hline 0 & 0.3023 & 356.266 & 334.12 & 317.14 & $2.01 \times 10^{6}$ & 1.51 & 24.802 \\
0 & 0.5026 & 439.936 & 398.87 & 327.33 & $3.15 \times 10^{6}$ & 1.60 & 23.721 \\
0 & 0.8049 & 518.588 & 459.82 & 384.33 & $4.34 \times 10^{6}$ & 1.86 & 21.511 \\
0 & 1.0025 & 664.997 & 591.62 & 468.04 & $5.55 \times 10^{6}$ & 1.81 & 21.746 \\
15 & 0.3028 & 288.847 & 256.26 & 214.36 & $1.54 \times 10^{6}$ & 1.96 & 28.294 \\
15 & 0.5029 & 342.919 & 294.67 & 233.29 & $2.07 \times 10^{6}$ & 2.43 & 27.672 \\
15 & 0.8035 & 473.569 & 404.16 & 295.94 & $3.00 \times 10^{6}$ & 2.68 & 26.414 \\
15 & 1.0027 & 515.112 & 441.46 & 327.24 & $3.83 \times 10^{6}$ & 2.62 & 26.433 \\
25 & 0.3029 & 256.199 & 227.24 & 205.58 & $1.10 \times 10^{6}$ & 2.76 & 32.439 \\
25 & 0.5006 & 304.159 & 244.89 & 171.25 & $1.49 \times 10^{6}$ & 3.36 & 31.758 \\
25 & 0.8023 & 410.194 & 342.64 & 235.47 & $2.32 \times 10^{6}$ & 3.46 & 30.562 \\
25 & 1.0045 & 466.105 & 400.68 & 323.88 & $2.98 \times 10^{6}$ & 3.37 & 30.190 \\
\hline
\end{tabular}

a The properties were calculated with the machine frame correction and tip area function correction. $h_{\mathrm{f}}$ : Displacement when unloading reaches $0 \mathrm{mN}(\mathrm{P}=0 \mathrm{mN})$. 


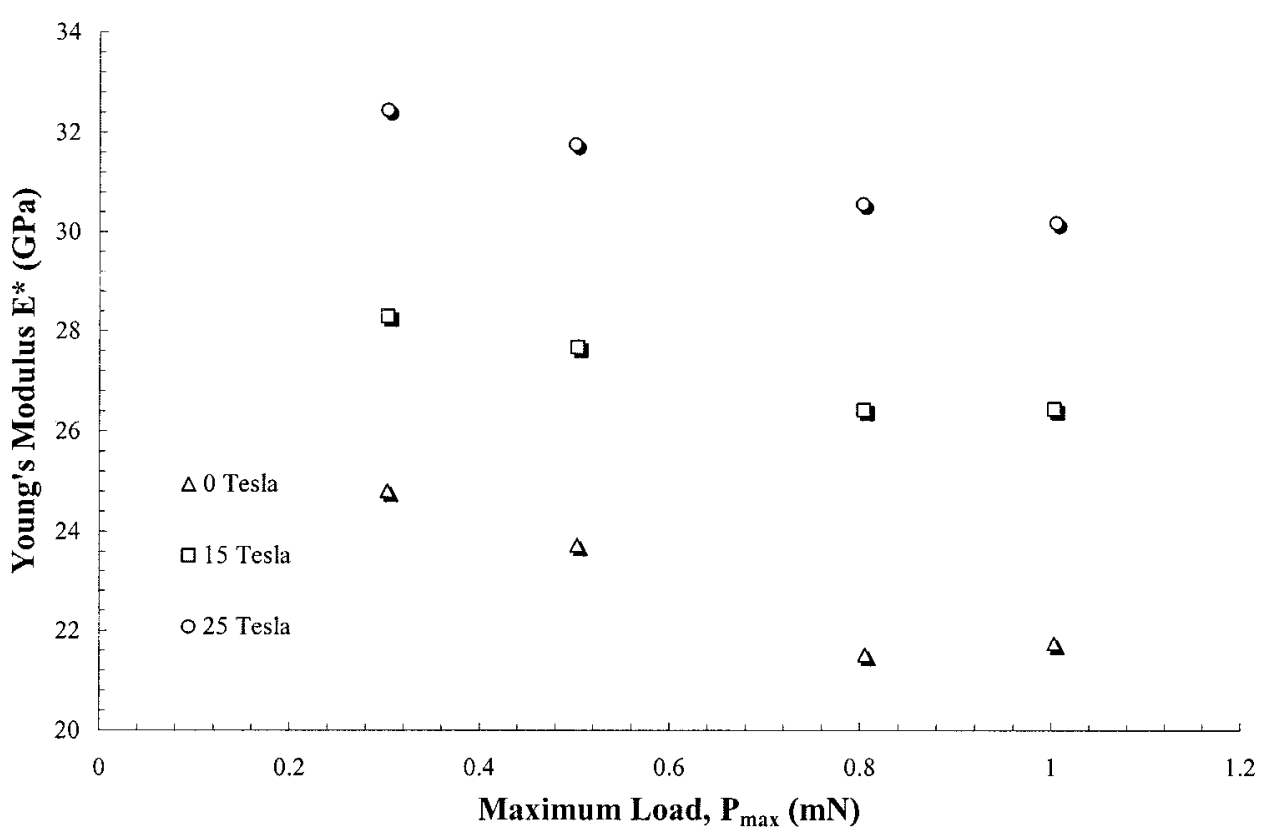

Figure 10. Variation of the elastic modulus of the epoxy with the magnetic-field strength and the maximum indentation load.

absence of a magnetic field. The increases in the modulus and hardness for the sample cured under $25 \mathrm{~T}$ were 30 and $82 \%$ higher than those for the sample cured outside the field. The indentation test gave a much higher value of the elastic modulus than the tensile tests for a bulk sample, as shown in Table 1.

One important factor is that the current samples were cured differently $\left(60{ }^{\circ} \mathrm{C}\right.$ for $\left.4 \mathrm{~h}\right)$. Another factor is the difference in the specimen size. The tensile modulus is measured on the available sections of specimens. The volume of the section loaded by tension is much greater than the compressed contact zone by indentation tests. Also, the indentation includes both tensile and compression loadings, which have different loading rates than a standard tensile test. Finally, the high modulus values were probably affected by viscoelastic creep, which can increase the initial slope of the unloading curve.

Nevertheless, the trends are similar for all the epoxy samples tested; therefore, if these intrinsic errors cannot be eliminated, the relative values of the hardness and elastic modulus evaluated against a reference material can be used for comparison.

Figures 10 and 11 show the variations of the elastic modulus and hardness as a function of both the magnetic-field strength and the maximum indentation load. Clearly, both the hardness and modulus attained higher values as the magnetic-field strength increased. The fact that Young's modulus evaluated at near-to-surface layers was higher in magnitude than the bulk values can be attributed to minor modifications of the material physical properties due to the exposure of the epoxy to environmental effects, such as light and air, before the experiments. The outer surface of a polymeric sample starts to solidify first, and because it is the most exposed to both light and oxidization, it is more likely to have higher hardness and modulus than the core of the sample. Briscoe et al. ${ }^{43}$ observed similar results for different polymeric systems such as PMMA, polystyrene, polycarbonate, and ultra-high-molecular-weight polyethylene.

Attractive adhesion forces are often encountered during tip retraction when soft materials are tested. Such adhesive forces are not normally observed in nanoindentation experiments with hard bulk materials or coatings, and they have been consistently overlooked in polymer nanoindentation studies. The application of instrumented indentation devices to the measurement of the elastic modulus of polymeric materials often leads to measurements of the elastic modulus that are somewhat high with respect to bulk measurements These problems are likely caused by viscoelasticity, the effects of which have only been studied recently. ${ }^{31,44}$ The current analysis of the 


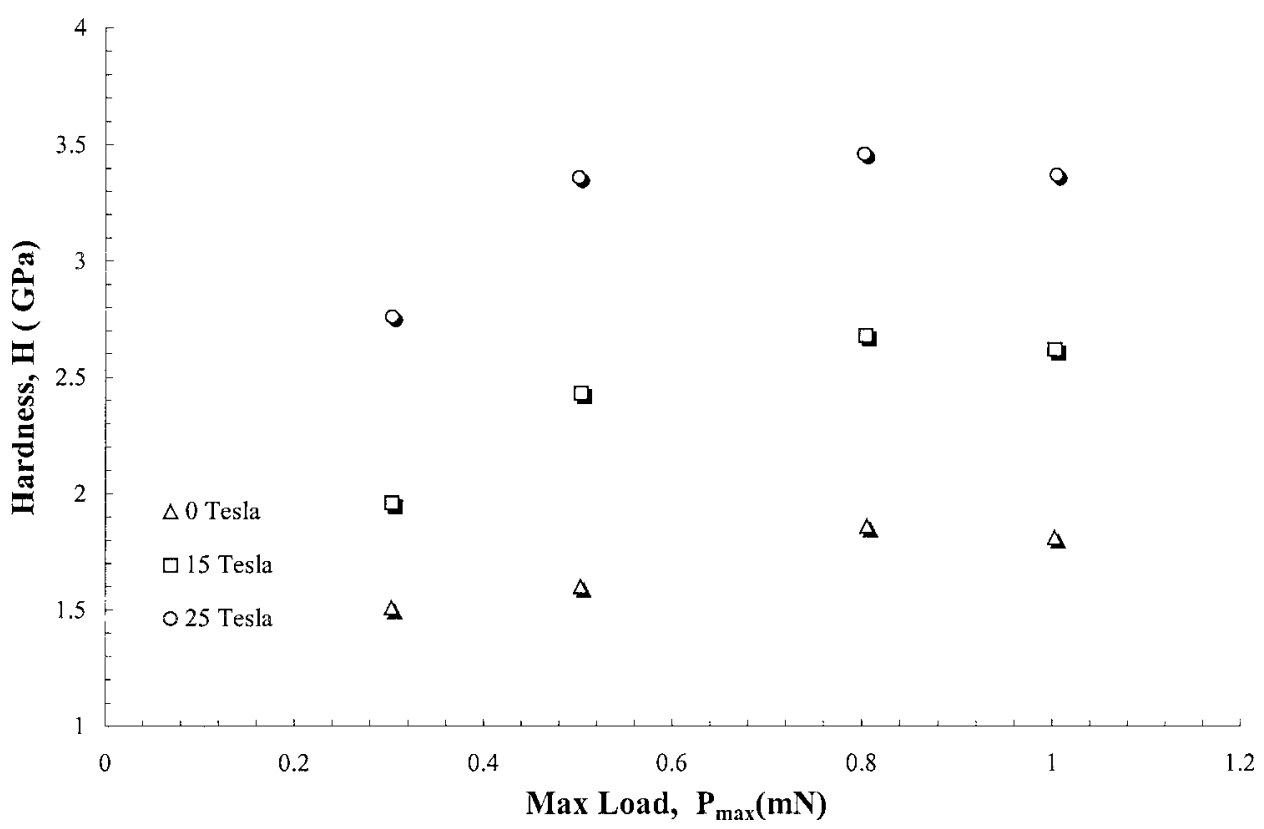

Figure 11. Universal hardness variation due to the magnetic-field strength and the maximum indentation load.

unloading data is based on elasticity, which, when applied to viscoelastic materials, can lead to large uncertainties in the calculated values of the modulus.

Moreover, the deliberate calculations carried out to calculate $h_{\mathrm{c}}$, the indenter tip area, and the machine frame stiffness have a direct and substantial influence on the resulting values of the computed hardness and elastic modulus. Experimental uncertainty in the initial zero point determination (for Unloading, $P=0$ ) and the deviation of the indenter geometry from the assumed perfect cone shape also contribute to the errors in the calculated modulus and hardness values. The intrinsic limitations of the calibration procedure adopted (the tip is calibrated on a hard surface such as that of fused silica) may not be completely avoided.

Van Landingham et al. ${ }^{31}$ concluded that measurements of $E$ with depth-sensing indentation (DSI) tend to increase with decreasing penetration depth; this is often called an indentation size effect. This artifact also appears to be a problem for the indentation of polymers with DSI; these trends result from increased uncertainties for shallow-depth indentations that are likely due to tip defects near the apex and decreased signal-tonoise ratios at low load and displacement levels. Also, values of $E$ measured for polymers with DSI are significantly higher than values measured with tensile testing or DMA. For example, Lucas $^{45}$ reported $E(\mathrm{DSI})=1.2 \mathrm{GPa}, E$ (tensile test) $=0.4 \mathrm{GPa}$, and $E(\mathrm{DMA})=0.5 \mathrm{GPa}$ for poly(tetrafluoroethylene). In another investigation, Kourtesis et al. $^{46}$ found the modulus of PMMA to be $3.27 \mathrm{GPa}$ with nanoindentation and $1.55 \mathrm{GPa}$ with uniaxial compression testing.

\section{CONCLUSIONS}

On the basis of this investigation, it is evident that magnetic alignment is a phenomenon closely related to the self-organizing process of the polymeric system. The microstructures of the polymer samples processed inside 15 - and 25-T fields were shown to have local orientation along the field's directions. WAXD showed a high degree of alignment when the azimuthal scan was parallel to the field direction $\left(\phi=90^{\circ}\right.$ and $\left.2 \theta=19^{\circ}\right)$. The alignment was proportional to the strength of the magnetic field. The pole figure analysis confirmed this observation.

DSI methods were used to measure the elastic modulus and hardness of the thermomagnetically processed epoxy. The elastic modulus for the magnetically cured epoxy samples $(25 \mathrm{~T})$ increased by $30-38 \%$, and the hardness increased by $80 \%$, in comparison with those of samples cured outside the magnetic field. The homogeneously oriented 
structures in the magnetically oriented epoxy were translated into enhanced mechanical properties of the epoxy system. Because the magnetic field is penetrable and its direction and strength are controllable, it is possible to fabricate materials with higher mechanical characteristics in which the alignment profile is specially designed.

This work was funded by the U.S. Army (DAAD 19-9910311 and DAAD 19-01-1-0742) and was performed at the National High Magnetic Field Laboratory (Tallahassee, FL). The authors gratefully acknowledge the experimental assistance of the pulsed magnet group and Robert Goddard from the material characterization group.

\section{REFERENCES AND NOTES}

1. Yuan, X.; Mak, A. F.; Kwok, K. W.; Yung, B.; Yao, K. J Appl Polym Sci 2001, 81, 251.

2. Greenblatt, J. H.; Fensom, D. Ind Eng Chem Res 1911, 39, 1037.

3. Kalay, G.; Bevi, M. J. J Polym Sci Part B: Polym Phys 1997, 35, 265.

4. Heynderickx, I.; Paridaans, F. Polymer 1993, 34, 4068 .

5. Lincoln, M. D.; Douglas, E. P. Polym Eng Sci 1999 , 39, 1903

6. Wang, Y.; Xiao, Y.; Zhang, Q.; Gao, X. L.; Fu, Q. Polymer 2003, 44, 1469.

7. Quintana, S. L.; Schmidt, P.; Dybal, J.; Kratochvý, J.; Pastor, J. M.; Merino, J. C. Polymer 2002, 43, 5187.

8. Martin, D. C. Polymer 2002, 43, 4421.

9. Korner, H.; Shiota, A.; Bunning, T. J.; Ober, C. K. Science 1996, 272, 252.

10. Shiota, A.; Ober, C. K. Macromolecules 1997, 30, 4278.

11. Benicewicz, B. C.; Smith, M. E.; Earls, J. D.; Priester, R. D.; Setz, S. M.; Duran R. S.; Douglas, E. P. Macromolecules 1998, 31, 4730.

12. Kimura, T.; Kawi, T.; Sakamot, Y. Polymer 2000, 41, 809-812.

13. Kawai, T.; Yakamoto, Y.; Kimura, T. Mater Trans 2000, 41, 955.

14. Ezure, H.; Kimura, T.; Ogawa, S.; Ito, E. Macromolecules 1997, 30, 3600.

15. Kossikhina, S.; Kimura, T.; Ito, E.; Kawahara, M. Polym Eng Sci 1997, 37, 396.

16. Anwer, A.; Windle, A. H. Polymer 1993, 34, 3347.

17. Kimura, T.; Yamato, M.; Koshimizu, W.; Koike, M.; Kawai, T. Langmuir 2000, 16, 858.

18. Volino, F.; Martins, A.; Blumstein, R. J Phys Lett (Paris) 1981, 42, 305.

19. Kossikhina, S. A.; Kimura, T.; Ito, E.; Kawahara, M. Polym Eng Sci 1998, 38, 921.
20. Manko, T. A.; Dzhur, E. A.; Sanin, F. P.; Ermolaev, I. M. Mech Compos Mater 2001, 37, 174.

21. Skourlis, T. P.; McCullough, R. Compos Sci Technol 1993, 49, 363.

22. Ken, M. G.; Kempf, M.; Bordenet, M.; Vehof, H. Surf Interface Anal 1999, 27, 302.

23. Nix, W. D. Mater Sci Eng A 1997, 234, 37.

24. Fang, T. H.; Chang, W. J. Microelectron Eng 2003, $65,231$.

25. Briscoe, B. J.; Fiori, L.; Pelillo, E. W. J Appl Phys D 1998, 31, 2395.

26. Oliver, W. C.; Pharr, G. M. J Mater Res 1992, 7, 1564.

27. Drechsler, D.; Karbach, A.; Fuchs, H. Appl Phys A 1998, 66, 825.

28. Brun, C.; Delobelle, P.; Fromm, M.; Berger, F.; Chambaudet, A.; Jaffiol, F. Mater Sci Eng A 2001, $315,63$.

29. Beake, B. D.; Leggett, G. J. Polymer 2002, 43, 319.

30. Amitay-Sadovsky, E.; Ward, B.; Somorjai, G. A.; Komvopoulos, K. J Appl Phys 2002, 91, 375.

31. Van Landingham, M. R.; Villarrubia, J. S.; Guthrie, W. F.; Meyers, G. F. Macromol Symp 2001, 167, 15.

32. Klapperich, C.; Komvopoulos, K.; Pruitt, L. J Tribol 2001, 123, 624.

33. Garmestani, H.; Al-Haik, M. S.; Dahmen, K.; Tannenbaum, R.; Li, D.; Sablin, S. S.; Hussaini, M. Y. Adv Mater 2003, 15, 1918.

34. Choi, E. S.; Brooks, J. S.; Eaton, D. L.; Al-Haik, M. S.; Garmestani, H.; Dahmen, K. J Appl Phys 2003, 94, 6034 .

35. Seitzman, L. E. J Mater Res 1998, 13, 2936.

36. Pharr, G. M. Mater Sci Eng A 1998, 253, 151.

37. Pharr, G. M.; Bolshakov, A. J Mater Res 2002, 17, 2660.

38. Wolf, B. Cryst Res Technol 2000, 35, 377.

39. Doerner, M. F.; Nix, W. D. J Mater Res 1986, 1, 601.

40. Li, D.; Garmestani, H.; Kalidindi, S. R.; Alamo, R. Polymer 2001, 42, 4903.

41. Li, D.; Garmestani, H. Polym Mater Sci Eng 2002, 86, 398.

42. Bartczak, Z.; Galeski, A.; Argon, A. S.; Cohen, R. E. Polymer 1996, 37, 2113.

43. Briscoey, B. J.; Fiori, L.; Pelillo, E. J Phys D: Appl Phys 1998, 31, 2395.

44. Van Landingham, M. R. J Res Natl Inst Stand 2003, 108, 249

45. Lucas, B. N; Rosenmayer, C. T.; Oliver, W. C. In Thin-Films-Stresses and Mechanical Properties VII; Cammarata, R. C.; Nastasi, M. A.; Busso, E. P.; Oliver, W. C., Eds.; Materials Research Society: Pittsburgh, PA, 1998; Vol. 505, p 97.

46. Kourtesis, G.; Renwick, G. M.; Fischer-Cripps, A. C.; Swain, M. V. J Mater Sci 1997, 32, 4493. 